\title{
22. FAILURE MODES OF TUFF SAMPLES FROM LEG 131 IN THE NANKAI ACCRETIONARY WEDGE $^{1}$
}

\author{
Jiaxiang Zhang, ${ }^{2,3}$ Daniel M. Davis, ${ }^{2}$ and Teng-fong Wong ${ }^{2}$
}

\begin{abstract}
Triaxial deformation tests were conducted for Leg 131 core samples (tuff) having porosities ranging from $25 \%$ to $40 \%$ under effective pressures up to $20 \mathrm{MPa}$. Samples saturated with distilled water were deformed under "drained" conditions at a nominal strain rate of $2.6 \times 10^{-5} / \mathrm{s}$. The porosity change was monitored, and the loading ram was stopped at different stages of deformation to allow for measuring permeability using the pulse decay technique. Compressional velocities were measured in nominally dry samples to infer the deformation-induced porosity change. Observation of the failure modes of the deformed samples showed that there exists a boundary, dependent upon both porosity and effective pressure, that separates the brittle and ductile regimes. Samples that are more porous and under a higher effective pressure deform more ductilely than less porous samples under lower effective pressures. The predicted behavior of the Nankai prism, based on the failure mode transition map and porosity data from Leg 131, is consistent with the observation of macroscopic homogeneous deformation by cataclastic flow. The presence of localized brittle failure at the toe of the Nankai prism (indicated by the documented occurrence of discrete faults, shear bands, and zones of breccia and scaly fabric) can be explained by locally induced pore pressures in excess of hydrostatic. We speculate that locally high pore pressures associated with shear zones reduce the effective pressure to below the critical value by enough to move the failure mode into the brittle regime, thereby explaining the discrete character of faults in a region that is otherwise macroscopically ductile.
\end{abstract}

\section{INTRODUCTION}

The deformational behavior of porous sediments in accretionary wedges at convergent margins is an important control on the tectonics of accretion.

Ocean Drilling Program (ODP) Leg 131 was successful in penetrating completely through a frontal thrust fault and a décollement zone at the toe of the Nankai accretionary wedge with good core recovery. The drilling provided useful shipboard data of structural fabrics (Taira, Hill, Firth, et al., 1991), showing that the overall deformation is macroscopically ductile in that the cataclasis seems to be homogeneously distributed. However, evidence of localized brittle failure also exists, as indicated by the documented occurrence of discrete faults, shear bands, and zones of breccia and scaly fabric. This leads to several interesting questions. Why is the deformation at the toe of the Nankai prism predominantly nonlocalized (or, in the sense that we use the term here, macroscopically ductile)? Under what conditions can brittle failure be induced? Can the observed inelastic behavior and failure modes be predicted on the basis of available shipboard data and laboratory tests?

In general, the failure mode is not specified in most continuum models of accretionary wedge tectonics that have been formulated (e.g., Chapple, 1978; Davis et al., 1983; Stockmal, 1983; Zhao et al., 1986). Therefore, they cannot provide a self-consistent explanation for the development of shear localization in the brittle regime. Karig (1990) recently showed how soil plasticity concepts (such as the critical state model formulated by Schofield and Wroth, 1968) can provide an overall framework for the analysis of failure processes at the toes of accretionary prisms. Such a model emphasizes the interplay of dilatational and compactive processes in governing the development of shear localization and cataclastic flow.

\footnotetext{
'Hill, 1.A., Taira, A., Firth, J.V., et al., 1993. Proc. ODP, Sci. Results, 131: College Station, TX (Ocean Drilling Program).

${ }^{2}$ Department of Earth and Space Sciences, State University of New York, Stony Brook, NY 11794, U.S.A.

${ }^{3}$ Now at AMOCO Production Company, P. O. Box 3385, Tulsa, OK 74102, U.S.A.
}

Recent laboratory studies of the failure of porous sandstones (Zhang et al., 1987; Scott and Nielsen, 1991) showed that the effective confining pressure (the difference between confining pressure and pore pressure) and initial porosity exert important controls over the brittle-ductile transition. Wong (1990) concluded that the sandstone behavior is in qualitative agreement with critical state soil mechanics from a phenomenological point of view. However, he also emphasized that the dominant mechanisms for cataclastic deformation in a lithified rock are grain crushing and pore collapse, which are significantly different from particulate flow (rearrangement of grains by relative rotation and slip) in soil.

If in-situ porosity and effective pressure are known, then the failure modes can be inferred from laboratory measurements. This approach seems to be applicable to the study of the deformation behavior of porous sediments at the toe of the Nankai accretionary wedge, where physical properties data (including both porosity and bulk density) were obtained during Leg 131. The effective overburden pressure (equivalent to the effective pressure in a triaxial configuration) can be inferred from the bulk density if the pore pressure distribution is known. Therefore, laboratory tests of the core sediments, combined with the porosity data and the effective confining pressures, can help constrain the deformation modes to be expected in an accretionary forearc.

To address these questions, we performed triaxial compression tests on Leg 131 core sediments under effective confining pressures up to $20 \mathrm{MPa}$. The porosities of these tested samples ranged from $25 \%$ to $40 \%$. In triaxial tests using these samples, we were able to document the transitions from brittle to ductile mode. Our experimental data were compiled in such a manner as to permit the construction of a brittle-ductile transition map as a function of porosity and effective confining pressure. The implications on the tectonics of a sedimentrich accretionary wedge at Nankai Trough will also be discussed.

\section{EXPERIMENTAL PROCEDURE}

\section{Core Samples Studied}

Tuff samples from two cores (having a diameter of $6.6 \mathrm{~cm}$ ) were tested in this study. One was obtained from Sample 131-808C-53R-3, $24-36 \mathrm{~cm}$, about 810 meters below the seafloor ( $\mathrm{mbsf}$ ), and the other 
from Sample 131-808C-101R-3, 59-87 cm (about $1260 \mathrm{mbsf}$ ). The porosity of the former (henceforth referred to as V1) is about $40 \%$ and that of the latter (labeled as V2) is about 30\% from shipboardbased measurement.

The configuration of an experimental sample is shown in Figure 1. The cylindrical test samples, $18.4 \mathrm{~mm}$ in diameter and $38.1 \mathrm{~mm}$ long, were prepared with the long axis parallel to the core axis. The jacket materials (copper foil and polyolefine) were used to separate the sample from the confining pressure medium, which was kerosene.

\section{Porosity Change and Permeability Measurements}

Except for the permeability and velocity measurements, the experimental techniques employed here were identical to those of Zhang et al. (1990). Samples were saturated with distilled water (Fig. 1A) and then subjected to a constant confining pressure of between 15 and $30 \mathrm{MPa}$ and a constant pore pressure of $10 \mathrm{MPa}$. The saturated samples were deformed under fully "drained" conditions at a nominal strain rate of $2.6 \times 10^{-5} / \mathrm{s}$. To measure pore volume change, we used a volumometer (Fig. 2 with valve 1 closed and valve 2 open) that can compensate for changes in pore volume within the sample and keep pore pressure constant. This pore volume change, which corresponds to the amount of fluid added to or taken from the sample, was recorded by monitoring the piston displacement of the volumometer with a displacement transducer (DCDT). Porosity change was then determined from the pore volume change divided by initial bulk volume of the sample, with an uncertainty of $\pm 0.1 \%$. The axial load was measured with an external load cell having an accuracy of $1 \mathrm{kN}$. The displacement was measured outside the pressure vessel with a DCDT installed between the moving piston and the fixed upper platen.

The elastic displacement of the loading system was corrected when we calculated the axial displacement of the sample, then the axial strain was calculated with respect to the initial length of the sample. When calculating the axial stress from the recorded axial force, we considered the average cross-sectional area change from bulging of the deformed sample. The relative increase in the crosssection area was estimated using the difference between the porosity change and the axial strain.

At various stages of deformation, the loading ram was stopped to allow us to determine permeability. Figure 2 is a schematic diagram of our permeameter set-up. Permeability was determined by the pulse decay method, developed by Brace et al. (1968). After the loading ram had been stopped, valve 1 was opened to connect the upstream of the sample with an accumulator, which acted as a pore-pressure buffer while maintaining pore pressure constant in spite of large changes in the fluid volume. Valve 2 was closed to separate the upstream and downstream reservoirs. A pressure pulse, $\Delta P_{\mathrm{o}}$ (less than $10 \%$ the magnitude of the total pore pressure), was generated in the downstream reservoir using the volumometer, and the differential pressure across the sample was then monitored by the differential pressure transducer (DPT).

According to the analysis of Brace et al. (1968), the differential pressure $\Delta P(t)$ decays exponentially as a function of time, $t$ :

$$
\Delta P(t)=\Delta P_{\mathrm{o}} \exp (-\alpha t)
$$

Plotting the decay curve in terms of $\log (\mathrm{DP})$ vs. time $t$ yields a straight line having a slope, $\alpha$, and the permeability, $K$, can be determined by

$$
K=\left(\alpha \mu L C_{\mathrm{d}}\right) / A,
$$

where $L$ is the length, $A$ the cross-sectional area of the sample, $\mu$ the dynamic viscosity of pore fluid, and $C_{\mathrm{d}}$ the downstream compressive storage (which was calibrated as $3.18 \times 10^{-8} \mathrm{~m}^{3} / \mathrm{MPa}$ for our set-up).

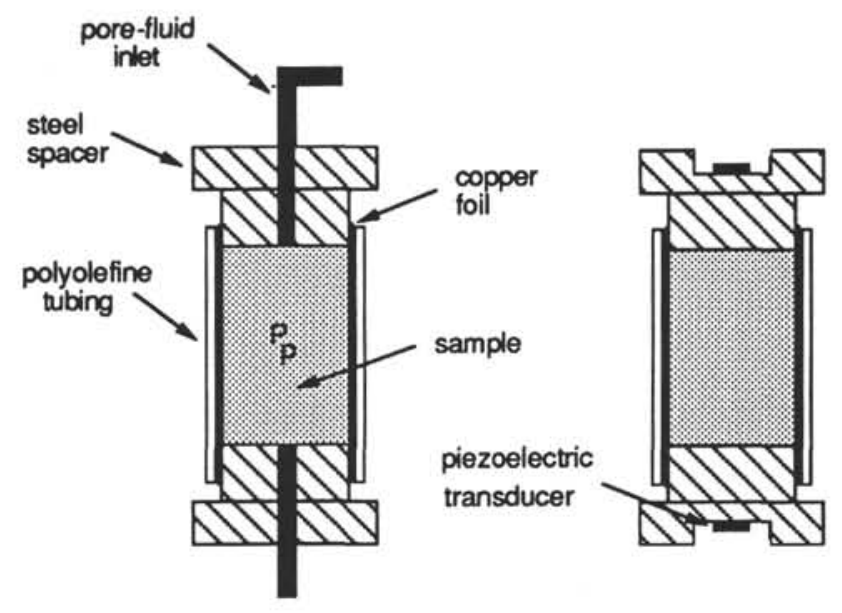

(A)

(B)

Figure 1. Sample configurations (A) used in our triaxial tests and permeability measurements under saturated conditions; (B) used in our triaxial tests and acoustic velocity measurements under dry conditions.

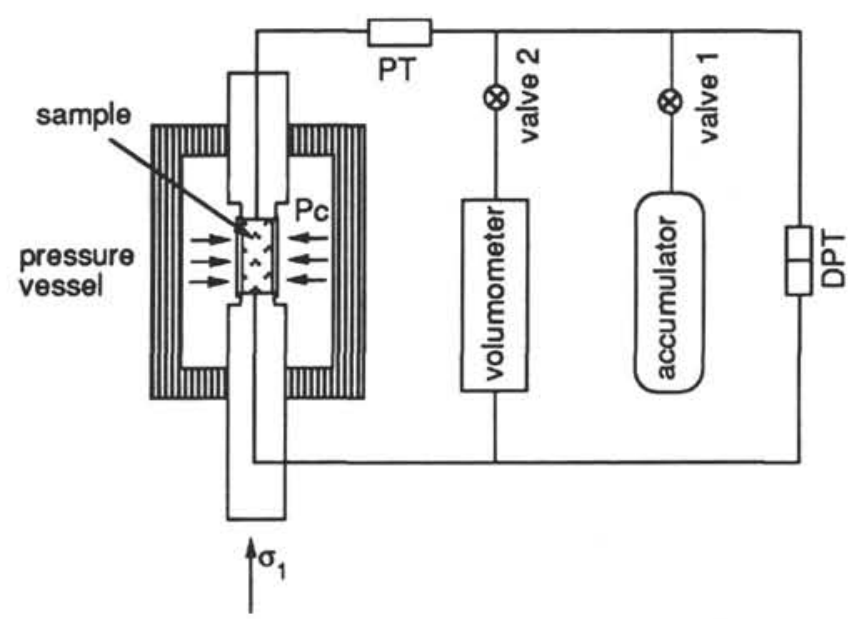

Figure 2. Schematic diagram of permeability measurement set-up used in our triaxial tests. PT = pressure transducer; DPT = differential pressure transducer.

\section{Compressional-Velocity Measurement}

Initially, we attempted to deform a saturated sample of the V1 core. However, the preliminary data indicate that significant timedependent creep occurred in the saturated sample, rendering it difficult to interpret the volumometer data. Therefore, we have had to adopt a different method to infer the porosity change indirectly. Nominally dry samples of the V1 core were deformed at a relatively fast strain rate of $10^{-4} / \mathrm{s}$, and compressional velocity measurements were conducted at different stages of deformation. An increase in velocity is generally expected to correlate with a reduction in porosity.

Two piezoelectric transducers (PZT-7, $5.0 \mathrm{~mm}$ diameter, 1-MHz longitudinal resonant frequency) were installed on the flat surface of each of two steel spacers attached to either side of the sample (Fig. 1B). An ultrasonic pulse signal was generated through one transducer, and the received signal from the other transducer was conditioned by a pre-amplifier before its first arrival was recorded by a digital storage oscilloscope. The measured traveltime was corrected 
for the additional delay time through the steel spacers, and the sample shortening during the triaxial test was taken into account.

\section{EXPERIMENTAL RESULTS}

\section{Mechanical Deformation Data}

Three nominally dry samples (V1-2, V1-5, and V1-10) from the V1 core were deformed at confining pressures of 2,5 , and $10 \mathrm{MPa}$, respectively. The differential stress and compressional velocity as functions of the axial strain are shown in Figure 3. Three saturated samples (V2-5, V2-10, and V2-20) from the V2 core were deformed at effective pressures of 5,10 , and $20 \mathrm{MPa}$, respectively. The differential stress and porosity change as functions of the axial strain are shown in Figure 4.

The deformation behavior of Samples V1-5 and V1-10 (Fig. 3A) are similar in that both samples show strain hardening up to an axial strain of more than $20 \%$. The Sample V1-2 (deformed at the lowest confining pressure) experienced strain hardening up to a peak differential stress at an axial strain of about $16 \%$, beyond which it softened. Macroscopically, Samples V1-5 and V1-10 were deformed homogeneously without signs of shear localization, and Sample V1-2 showed barely visible shear localization, indicating an intermediate behavior between brittle and macroscopically ductile. The velocities of V1-2 and V1-10 (Fig. 3B) show appreciable increase during the early stages of hardening, and beyond that, the velocities remained basically constant regardless of hardening or softening. Because increased velocity usually correlates with porosity reduction, the velocity data suggest that significant compaction occurred at the initial hardening stage.

Two markedly different failure modes were attained in Samples V2-5 and V2-20 (Figs. 4A and 4B). At the relatively low effective pressure of $5 \mathrm{MPa}$, a peak deviatoric stress was reached at an axial strain of about $2 \%$, beyond which the stress decreased to a lower level. The deformed Sample V2-5 has a fault at about $30^{\circ}$ to the axial loading direction. Porosity reduction occurred before the peak stress was reached, but no obvious porosity change was observed with further deformation. At the higher effective pressure of $20 \mathrm{MPa}$, a peak stress was reached at an axial strain of about $5 \%$. Although slight strain softening occurred beyond the peak stress, Sample V2-20 was deformed homogeneously up to an axial strain of more than $20 \%$ without any indication of shear localization. The porosity reduction persisted to an axial strain of $15 \%$. The third sample, V2-10, showed an intermediate type of behavior with distributed shear bands.

\section{Permeability Data}

Figure $4 \mathrm{C}$ shows permeability as a function of axial strain for the two samples, V2-5 and V2-20. The permeability decreased with increasing deformation, and most of the permeability reduction occurred during the initial stage of deformation, before the differential stress reached a peak value. At a fixed effective pressure, permeability reduction shows a positive correlation with porosity reduction (Fig. 4B).

Note that the permeability reduction was more pronounced in Sample V2-5, which deformed brittlely, even though its porosity reduction was significantly less than that of Sample V2-20, in which deformation was macroscopically ductile. According to theoretical analyses of the relationship between permeability and porosity (e.g., Bear, 1972), a negative correlation between permeability and porosity can arise if the more porous sample has a higher tortuosity. The observed dramatic decrease in permeability in the brittle Sample V2-5 may possibly have resulted from a significant increase in tortuosity at the onset of shear localization. Arch and Maltman (1990) recently argued that shear strain accumulated along a brittle fault will cause the permeability and tortuosity to be highly anisotropic. Unfortunately, our present system is not capable of characterizing the development of this type of anisotropy.
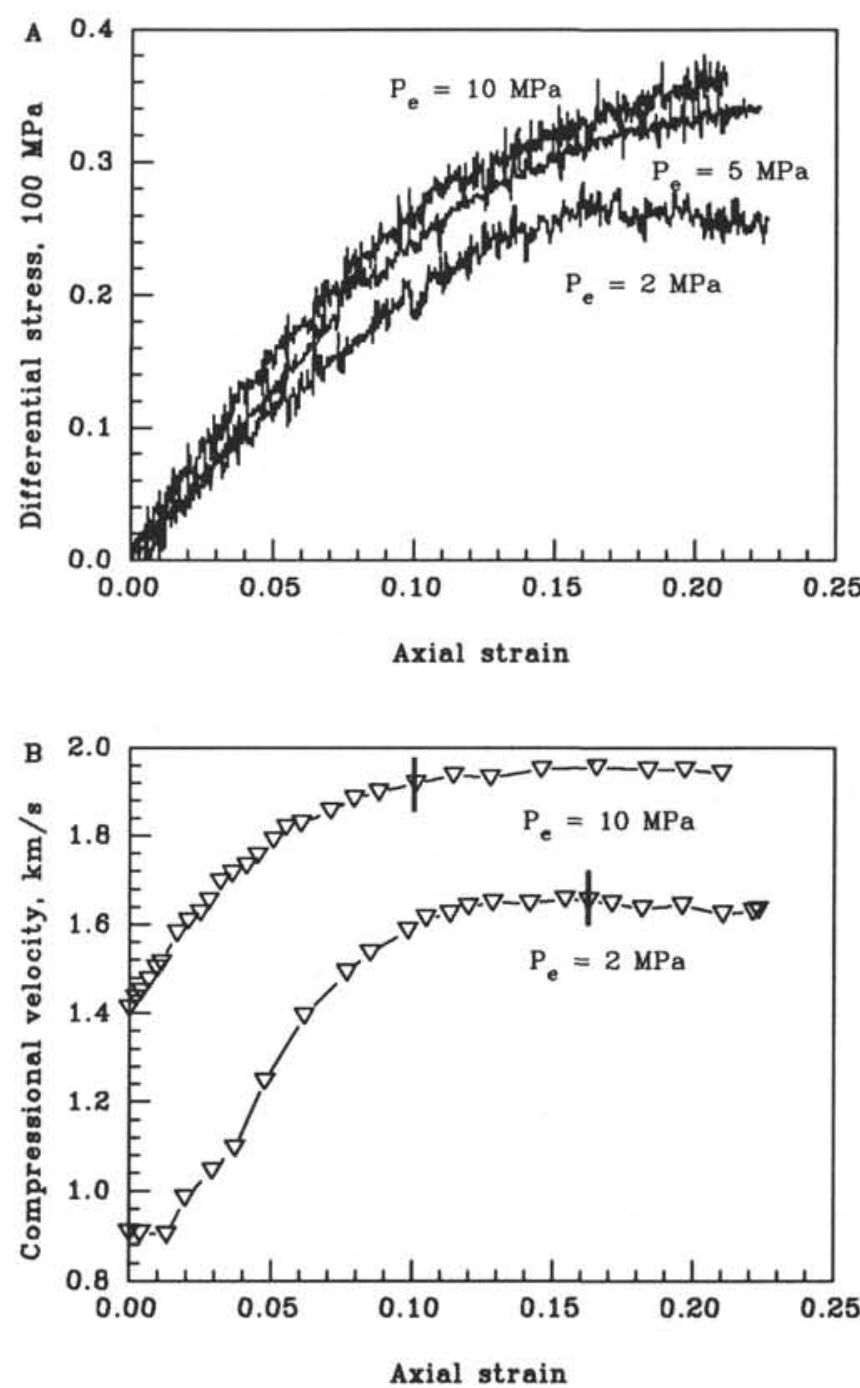

Figure 3. The stress-strain and acoustic velocity data of V1 samples under dry conditions: (A) differential stress-axial strain data at three confining pressures of 2, 5, and $10 \mathrm{MPa}$; (B) compressional velocity-axial strain data at two confining pressures of 2 and $10 \mathrm{MPa}$. The error bars indicate uncertainties in the velocity measurement.

\section{Electron Microscope Observations}

Sections parallel to the axial loading direction were cut from the middle part of the V2 samples, and we conducted preliminary scanning electron microscope (SEM) observations (PI. 1) to investigate the stress-induced changes in the pore structure. A throughgoing fault cuts through the sample (V2-5) deformed in the brittle regime, and the SEM observations show that the shear localization was the result of the coalescence of transgranular and intergranular microcracks. The inferred increase in tortuosity we discussed above may somehow be related to this stress-induced microcracking. Our observations about the grain size and pore dimension distribution of the stressed and undeformed samples ( $\mathrm{Pl}$. 1) suggest that pore collapse and grain crushing occurred in the deformed Sample V2-5. Similar microstructural features were observed in DSDP samples from zones of frontal accretion near Barbados and Kodiak (Lucas and Moore, 1986) that reveal intense cataclastic shear zones caused by tectonically induced shear stresses. 


\section{DISCUSSION}

The tuff cores from Leg 131 are more porous than materials usually studied in rock mechanics and are subjected to a higher overburden pressure than the porous soils studied in geotechnical engineering. To gain a broader understanding of their hydromechanical behavior, we performed triaxial tests on Leg 131 core tuffs under effective pressures from 2 to $20 \mathrm{MPa}$ in a range of porosities from $25 \%$ to $40 \%$.

Two kinds of failure modes were documented in this study. In the first mode, the sample failed by shear localization with strain softening and dilatancy. This failure mode will be referred to as "brittle." In the second mode, the sample failed by homogeneous cataclastic flow with overall compactive strain and no signs of shear localization. This failure mode will be referred to as "ductile." In Figure 5, we summarize our failure mode data in a space of effective pressure and porosity. The solid circle corresponds to the brittle regime, with a shear fault developed along one throughgoing slip plane in the sample. The open circles mark the effective confining pressures and porosities under which the samples were deformed in a ductile mode with homogeneously distributed cataclastic flow. The solid line connecting the crossed circles (corresponding to intermediate behavior) represents a schematic brittle-ductile transition boundary. The porosity value corresponds to that of a sample before the application of the differential stress, but after the hydrostatic compaction. The hydrostatic compaction for the V2 samples was calculated from the volumometer measurements. For the V1 samples, we inferred the hydrostatic compaction from the axial strain, assuming the porosity reduction to be isotropic.

This transition map is qualitatively consistent with previous results on porous sandstones (Zhang et al., 1987; Wong, 1990; Scott and Nielsen, 1991) in that more porous samples under higher effective pressures deform more ductilely than less porous samples under lower effective pressures. In other words, increasing the porosity and the effective pressure should promote the transition from brittle faulting to homogeneous cataclastic flow.

Combined with the distributions of porosity and effective confining pressure in an accretionary wedge, the transition map helps us to address basic questions about the mechanical behavior of porous sediments that have been subjected to deformation due to tectonically induced stresses at active margins. Leg 131 provided a unique opportunity to document the physical properties of the core sediments from burial depths completely across through the toe of the Nankai accretionary prism. The porosity profile as a function of buried depth below seafloor from Leg 131 (Taira, Hill, Firth, et al., 1991 ) is shown in Figure 6. The stress configuration at an accretionary wedge is such that the orientation of the maximum principal stress $\sigma_{1}$ is subhorizontal, and the minimum stress $\sigma_{3}$ is essentially equal to the overburden pressure. As a first approximation, the effective overburden pressure can be taken as equivalent to the effective confining pressure in a triaxial compression test.

The small diamonds in Figure 5 correspond to the Leg 131 porosity data in Figure 6, with the assumption that the bulk density of the sediments is $2 \mathrm{~g} / \mathrm{cm}^{3}$ and that the pore pressure is everywhere hydrostatic. The data at low effective overburden pressures are scattered because of poor quality of the loose sediments and drilling disturbance. The obvious offset in the data at about $10 \mathrm{MPa}$ effective overburden pressure coincides with a décollement surface across which the porosity is offset by $10 \%$. The comparison between the transition map and the porosity data, most of which are located in the ductile zone in Figure 5, clearly suggests that the overall deformation of the sediments is dominantly ductile, if the pore pressure is nearly hydrostatic.

The documented structural data during Leg 131 showed discrete faults, shear bands, and zones of breccia and scaly fabric that are indicative of localized brittle failure. In particular, the frontal thrust and the décollement zone are clearly recognizable in both the core samples and seismic profile. These brittle features seem to contradict the prediction from Figure 5 that overall deformation involves homo-
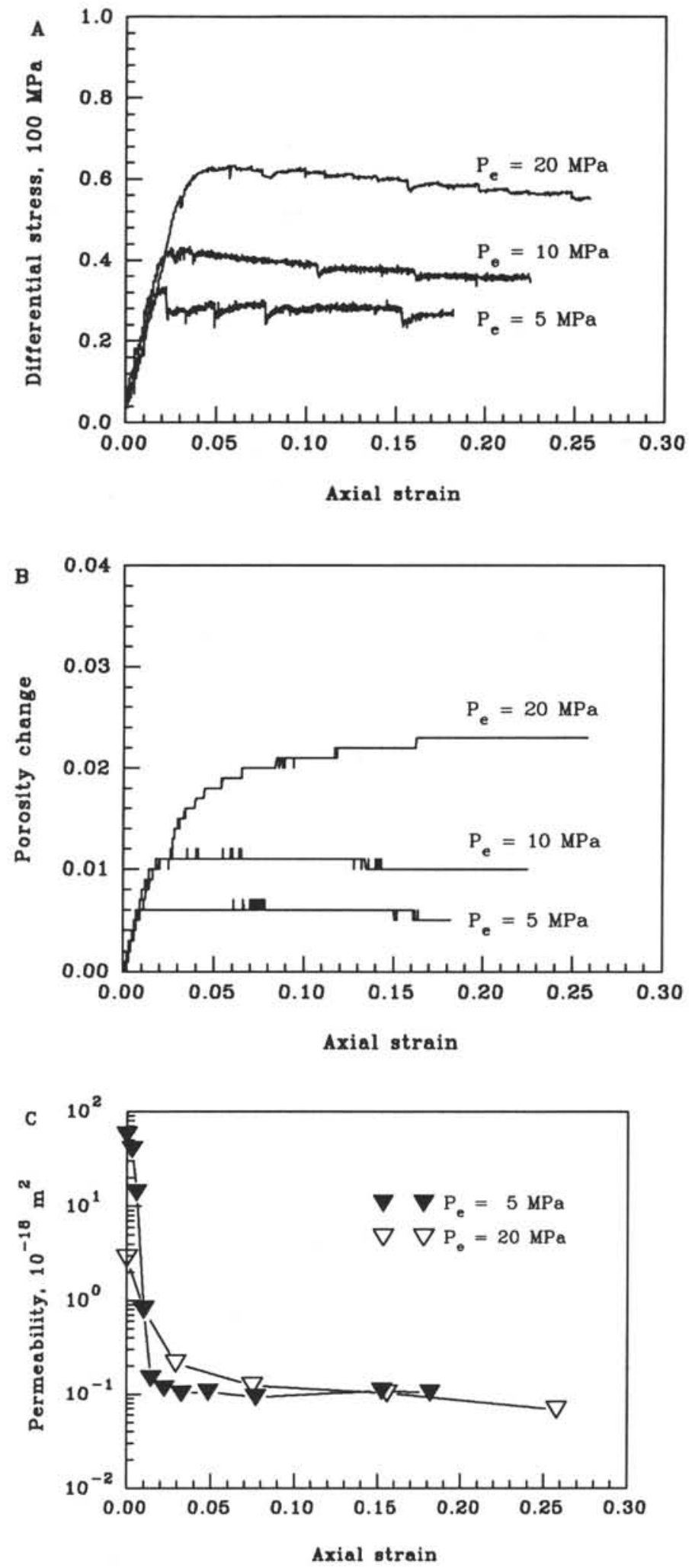

Figure 4 . The stress-strain, porosity change, and permeability data of V2 samples under effective pressures of 5, 10, and $20 \mathrm{MPa}$ : (A) differential stress-axial strain data; (B) porosity change-axial strain data; (C) permeability-axial strain data. 


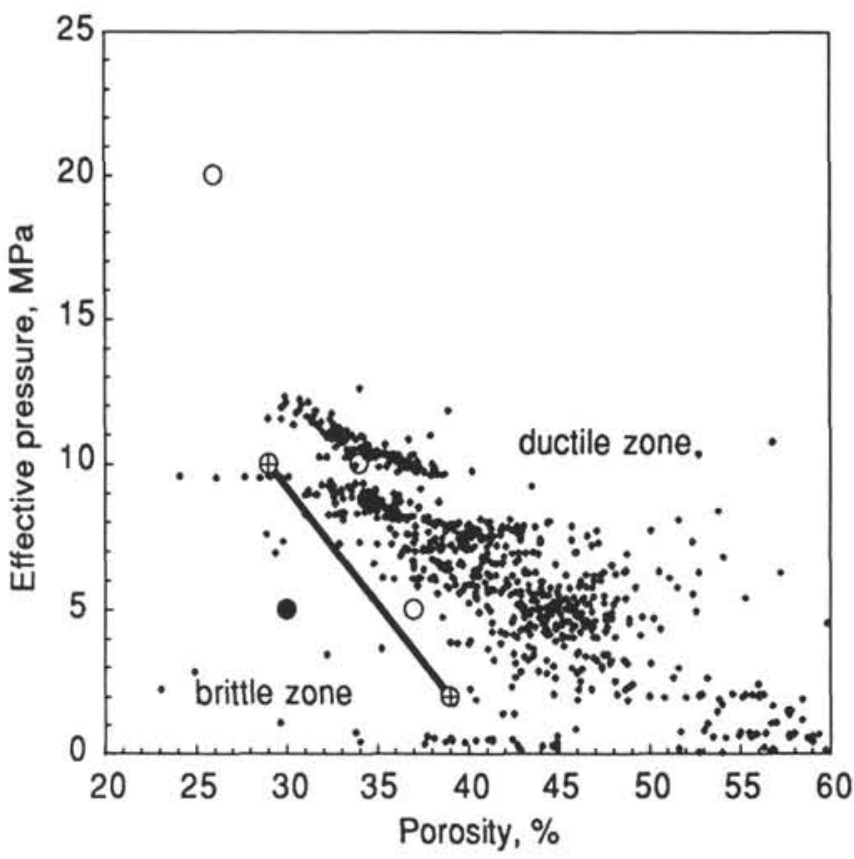

Figure 5. Brittle-ductile transition map based on our triaxial test data. The solid circle represents brittle behavior, the open circles represent ductile deformation, and the crossed circles show intermediate behavior. The V1 samples have porosities in the range of $34 \%$ to $40 \%$, and the V2 samples have porosities in the range of $25 \%$ to $30 \%$. A brittle-ductile transition boundary as shown by the solid line connecting the crossed circles separates the brittle zone from the ductile zone. . Diamonds = porosity data based on Leg 131 porosity data (Fig. 6), where depths were converted to effective overburden pressure and with an assumption of hydrostatic pore pressure distribution.

geneous distributed cataclastic flow. A decrease in either porosity or effective pressure might change the failure mode from ductile to brittle. Because the porosity data shown in Figures 5 and 6 are fairly robust, it is likely that localized brittle failure is associated with effective pressures lower than those shown in Figure 5, thus implying that pore pressures may be in excess of hydrostatic. Frictional critical taper models (e.g., Davis et al., 1983) generally require that the sediments in the zones of faulting in most accretionary wedges be at least somewhat overpressured and suggest that, in some cases, they may be close to lithostatic (Zhao et al., 1986). The development of brittle shear resulting from overpressuring is also suggested from the porosity offset across the shear zones (Taira, Hill, Firth, et al., 1991). Although the effect is not expected to be significant, some differences in failure mode between the laboratory and field setting may arise due to the relatively slow strain rate, elevated temperature, and large strain not accounted for in our experiments. A decrease in strain rate and an increase in temperature may increase the ductility by the activation of creep processes. On the other hand, a laboratory sample that failed in a ductile manner by cataclastic flow might plausibly develop a shear fault if the deformation was allowed to accumulate to very high strain.

Our permeability measurements for the tuff samples are in the microdarcy range. According to Brace's analysis (1980), such permeability values are probably not low enough to maintain a pore pressure excess over a prolonged period of time. On the other hand, laboratory studies (e.g., Morrow et al., 1984; Yassir, 1990) also indicate that clay-rich sequences are capable of sustaining high pore pressure excess because of the relatively low permeability and high compressibility of clay minerals. Where an abundance of clay exists in an accretionary prism, our tuff data (Fig. 4) would represent upper bound values for the in-situ permeability.
Our samples are volcanic sediments having a coarse grain size. Although these were indurated, we encountered extreme difficulties when preparing samples of testing size; thus, only a limited number of samples were available for constructing the transition map. In dealing with porosity data from Leg 131, we neglected porosity rebound. Based on measurements by Hamilton (1976), the most significant porosity rebound at shallow depths down to $300 \mathrm{~m}$ is about $5 \%$ and the amount of the rebound decreases as burial depth. On the other hand, when constructing our transition map (Fig. 5), we considered only the initial porosity before triaxial stress was applied. Given the large uncertainties in the porosity data, complete consideration of elastic rebound in porosity data and shear-induced porosity reduction from triaxial tests would not be warranted at this stage. In summary, our experimental results indicate that deformation near the toe of the Nankai wedge is predominantly nonlocalized (i.e., macroscopically ductile even though the microscopic deformation mechanisms may brittle cataclasis). However, once zones of shearing develop, they may affect the build-up of excess pore fluid pressure sufficiently to move the failure mode into the localized brittle regime. This might then explain the presence of discrete faults in accretionary wedge toe that is otherwise predominantly characterized by macroscopic ductile.

\section{ACKNOWLEDGMENTS}

This research was supported by a JOI/USSAC grant. D.M. Davis acknowledges the support of NSF grant OCE-8915473. J. Zhang was also supported by a JOI/USSAC Ocean Drilling Fellowship. Comments by F.M. Chester and Toshihiko Shimamoto have been very useful.

\section{REFERENCES}

Arch, J., and Maltman, A., 1990. Anisotropic permeability and tortuosity in deformed wet sediments. J. Geophys. Res., 95:9035-9045.

Bear, J., 1972. Dynamics of Fluids in Porous Media: New York (Dover Publications).

Brace, W.F., 1980. Permeability of crystalline and argillaceous rocks. Int. J. Rock Min. Sci., 17:241-251.

Brace, W.F., Walsh, J.B., and Frangos, W.T., 1968. Permeability of granite under high pressure. J. Geophys. Res., 73:2225-2236.

Chapple, W.M., 1978. Mechanics of thin-skinned fold-and-thrust belts. Geol. Soc. Am. Bull., 89:275-304.

Dahlen, F.A., Suppe, J., and Davis, D.M., 1984. Mechanics of fold-and-thrust belts and accretionary wedges: cohesive Coulomb theory. J. Geophys. Res., 89:10087-10101.

Davis, D.M., Suppe, J., Dahlen, F., 1983. Mechanics of fold-and-thrust belts and accretionary wedges. J. Geophys. Res., 88:1153-1172.

Hamilton, E.L., 1976. Variations of density and porosity with depth in deep sea sediments. J. Sediment. Petrol., 46:280-300.

Hoshino, K., Koide, H., Inami, K., Iwamura, S., and Mitsui, S., 1972. Mechanical properties of Japanese Tertiary sedimentary rocks under high confining pressure. Geol. Surv. Jpn., 244.

Karig, D.E., 1990. Experimental and observational constraints on the mechanical behavior in the toes of accretionary prisms. In Rutter, R.J., and Rutter, E.H. (Eds.), Deformation Mechanisms, Rheology and Tectonics. Geol. Soc. Spec. Publ. London, 54:383-398.

Lucas, S.E., and Moore, J.C., 1986. Cataclastic deformation in accretionary wedges: Deep Sea Drilling Project Leg 66, southern Mexico, and on-land examples from Barbados and Kodiak islands. In Moore, J.C. (Ed.), Structural Fabrics in Deep Sea Drilling Project Cores from Forearc. Mem.Geol. Soc. Am., 166:89-103.

Morrow, C.A., Shi, L.Q., and Byerlee, J.D., 1984. Permeability of fault gouge under confining pressure and shear stress. J. Geophys. Res., 89:3193-3200.

Schofield, A., and Wroth, P., 1968. Critical State Soil Mechanics: London (McGraw Hill).

Scott, T.E., and Nielsen, K.C., 1991. The effects of porosity on the brittle-ductile transition in sandstones. J. Geophys. Res., 96:405-414.

Stockmal, G.S., 1983. Modeling of large scale accretionary wedge deformation. J. Geophys. Res., 88:8271-8287. 
Taira, A., Hill, I., Firth, J.V., et al., 1991. Proc. ODP, Init. Repts., 131: College Station, TX (Ocean Drilling Program), 71-269.

Wong, T.-F., 1990. Mechanical compaction and brittle-ductile transition in porous sandstones. In Rutter, R.J., and Rutter, E.H. (Eds.), Deformation Mechanisms, Rheology and Tectonics. Geol. Soc. Spec. Publ. London, $54: 111-122$.

Yassir, N.A., 1990. The undrained shear behavior of fine-grained sediments. In Rutter, R.J., and Rutter, E.H. (Eds.), Deformation Mechanisms, Rheology and Tectonics. Geol. Soc. Spec. Publ. London, 54:399-404.

Zhang, J., Wong, T.-F., and Davis, D.M., 1987. Failure mode as a function of porosity and effective pressure in porous sandstones. Geol. Soc. Am. Abstr. Programs, 19:904. (Abstract)
1990. High pressure embrittlement and shear-enhanced compaction of Berea sandstone: acoustic emission measurement and microstructural observation. In Hustrulid, W.A., and Johnson, G.A. (Eds.), Rock Mechanics Contributions and Challenges, 653-660.

Zhao, W.L., Davis, D.M., Dahlen, F.A., and Suppe, J., 1986. Origin of convex accretionary wedges: evidence from Barbados. J. Geophys. Res., 91:10246-10258.

Date of initial receipt: 25 September 1991

Date of acceptance: 5 June 1992

Ms 131SR-114

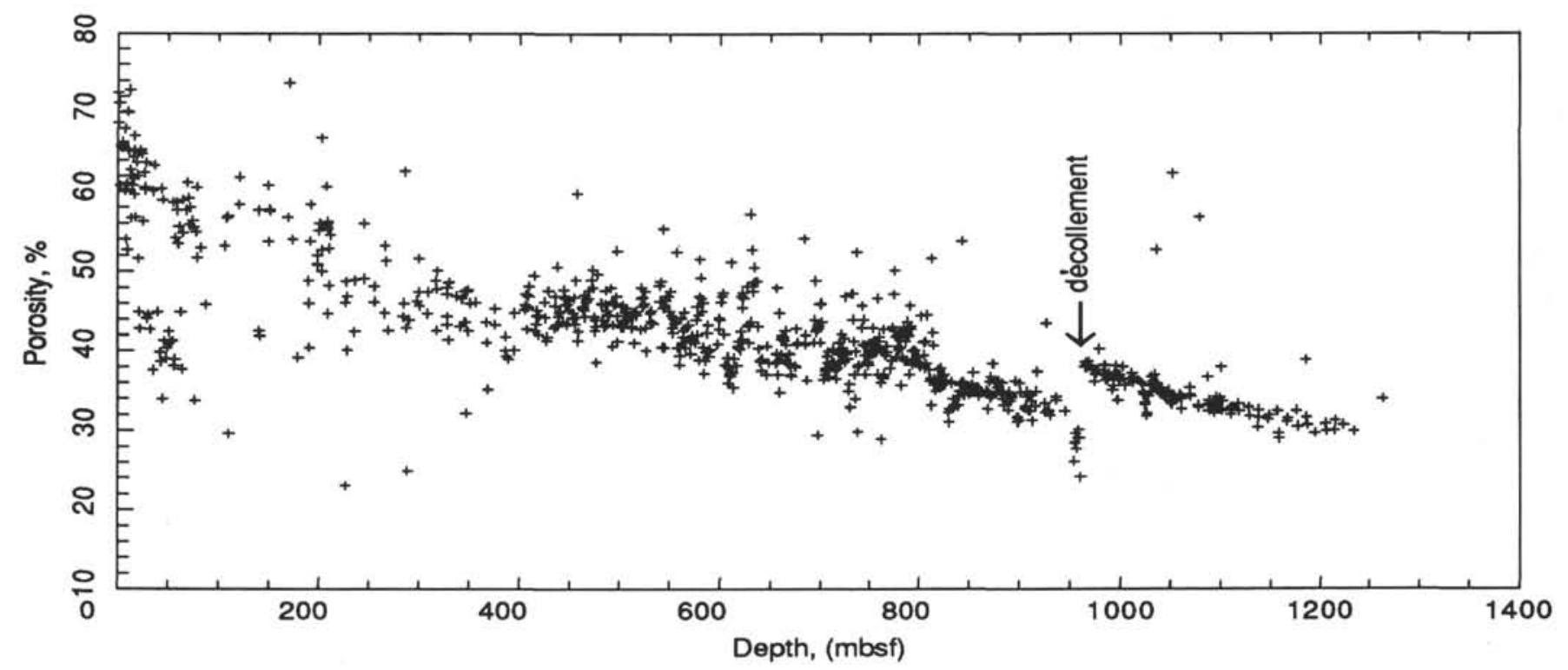

Figure 6. Porosity-depth data of Site 808, Leg 131 (Taira, Hill, Firth, et al., 1991). 

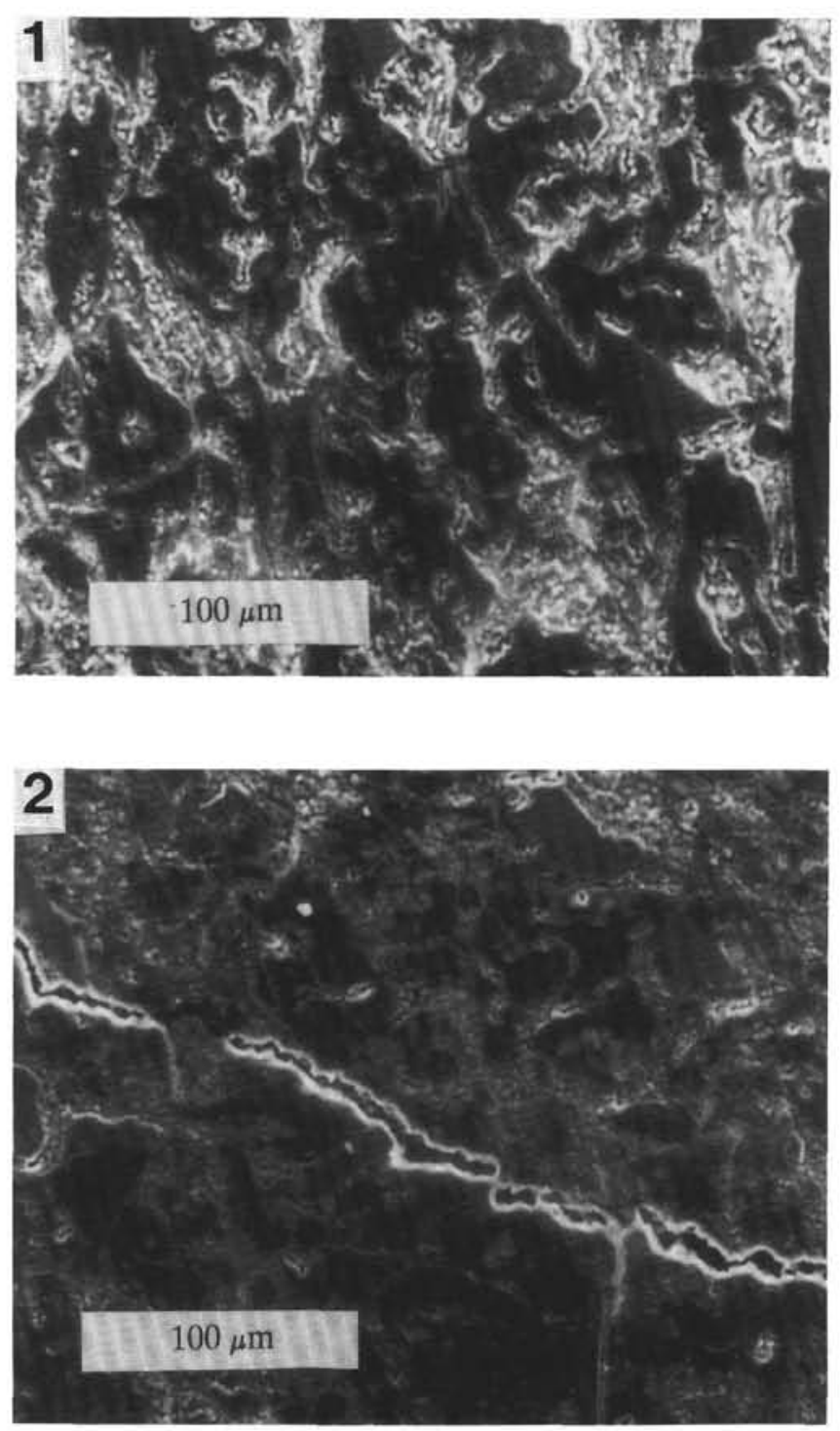

Plate 1. SEM microphotographs of V2 samples. 1. From an undeformed sample. 2. From V2-5 sample, which deforms brittlely at an effective pressure of $5 \mathrm{MPa}$, showing significant grain size reduction in the shear localized zone. The maximum principal (compressive) stress is horizontal. 